\title{
PENERAPAN MALCOLM BALDRIGE DALAM SISTEM PENILAIAN KINERJA MANAJEMEN BIDANG KESEHATAN
}

\author{
Citra Wiguna ${ }^{1}$, Yudha Saintika ${ }^{2}$ \\ Program Studi S1 Sistem Informasi, Fakultas Teknologi Industri dan Informatika, \\ Intitut Teknologi Telkom Purwokerto, J1. D. I. Panjaitan No. 128, 53147, Purwokerto, \\ Indonesia
}

\begin{abstract}
Abstrak-Rumah sakit dituntut untuk mampu meningkatkan mutu dan mempertahankan standar pelayanan yang memenuhi standar internasional secara keseluruhan. Dalam hal ini, diperlukan sebuah sistem penilaian kinerja manajemen bidang kesehatan untuk mendapatkan informasi mengenai level kinerja manajemen rumah sakit. Penelitian ini membangun suatu sistem penilaian kinerja manajemen bidang kesehatan dengan Malcolm Baldrige. Malcolm Baldrige merupakan kerangka kinerja yang sesuai dengan standar internasional dan digunakan dalam pengukuran kinerja manajemen rumah sakit. Indikator/kriteria dalam penelitian ini yaitu: kepemimpinan; perencanaan strategi; fokus pasien; pelanggan lain dan pasar; pengukuran analisis dan manajemen; fokus tenaga kerja; fokus operasi kerja dan hasil. Hasil penelitian ini berupa sistem penilaian kinerja manajemen rumah sakit yang dapat memberikan informasi level kinerja rumah sakit. Penelitian ini menunjukkan rumah sakit berada pada level "industry leader" dengan skor 677,20. Hal ini menunjukkan bahwa penerapan kerangka Malcolm Baldrige tepat diterapkan dalam sistem penilaian kinerja manajemen bidang kesehatan.
\end{abstract}

Keywords-sistem penilaian kinerja, Malcolm Baldrige, indikator kinerja.

\section{Pendahuluan}

Bidang kesehatan merupakan salah satu sektor yang berkaitan langsung dengan kehidupan masyarakat, karena itu penyediaan kebutuhan akan pelayanan kesehatan harus diutamakan. Rumah sakit adalah institusi pelayanan kesehatan bagi masyarakat dengan karateristik tersendiri yang dipengaruhi oleh perkembangan ilmu pengetahuan kesehatan, kemajuan teknologi dan kehidupan sosial ekonomi masyarakat yang harus tetap mampu meningkatkan pelayanan yang lebih bermutu dan terjangkau oleh masyarakat agar terwujud derajat kesehatan yang setinggitingginya [1].

Dalam peranannya rumah sakit dituntut untuk mampu memberikan pelayanan yang bermutu sesuai dengan standar yang ditetapkan dan dapat menjangkau seluruh lapisan masyarakat (DepKes RI, 2008). Standar yang sudah digunakan oleh beberapa rumah sakit untuk mengukur kinerja manajemennya seperti: Komite Akreditasi Rumah Sakit (KARS), Joint Commision International (JCI), ISO 9000, Balanced scorecard dan sistem manajemen mutu lainnya untuk perbaikan kualitas layanan.

Untuk meningkatkan mutu dan mempertahankan standar pelayanan rumah sakit maka perlu sebuah penilaian kinerja. Penilaian kinerja Rumah sakit sangat sulit dan kompleks untuk dilakukan, dibutuhkan informasi lebih dalam bidang non finansial. Sistem penilaian kinerja dilakukan dengan tujuan mengendalikan, memonitoring dan memperbaiki kualitas pelayanan perusahaan kesehatan (Lin, Liu, Liu, \& Wang, 2013).

Agar penilaian kinerja dapat dilaksanakan dengan tepat, perusahaan perlu menetapkan indikator kinerja yang relevan. Indikator kinerja tidak hanya berupa indikator keuangan tetapi juga indikator non keuangan terutama untuk mengukur hasil (outcome). 
Pada tahun 1987 National Institute of Standards and Technology (NIST) mengembangkan Malcolm Baldrige National Quality Award (MBNQA) dengan tujuan dasar mempromosikan kesadaran mutu kualitas yang diakui serta disebarkan oleh perusahaan Amerika. Pada awalnya, MBNQA terbatas untuk manufaktur dan usaha pelayanan profit saja, namun tahun 1995, MBNQA dikembangkan khusus untuk perusahaan bidang kesehatan (Goldstein \& Schweikhart, 2002).

Malcolm Baldrige Criteria for Performance Excellence merupakan penuntun bagi suatu perusahaaan untuk mencapai kinerja bermutu tinggi. Terdiri dari 7 kriteria yaitu Kepeminpinan; Perencanaan strategi; Fokus Pasien, Pelanggan lain dan Pasar; Pengukuran, Analisis dan Manajemen Pengetahuan; Fokus Tenaga Kerja; Fokus Operasi Kerja; dan Hasil. Keunggulan dari kriteria Balridge adalah kemampuannya untuk memberikan penilaian secara menyeluruh dan terpadu. Pengukuran kualitas menggunakan kriteria Baldrige memberi keuntungan karena memungkinkan perusahaan melakukan penilaian mandiri (self-assessment) (Gaspersz dan Fontana, 2011). Selain mempunyai kriteria yang lengkap dan sesuai dengan standar internasional, kriteria Malcolm Baldrige pun mempunyai ketergantungan antar satu kriteria dengan kriteria lainnya (Meyer Goldstein, Collier, Meyer, \& Collier, 2001).

Salah satu penelitian dalam penilaian kinerja yaitu menggunakan Kerangka Balanced Scorecard dan metode fuzzy linguistik juga diterapkan dalam evaluasi kinerja pada ruang operasi (operating room) untuk mengukur dan meningkatkan kinerja ruang operasi. Menggunakan 4 perspektif dasar yaitu: keuangan; pelanggan; bisnis proses internal; pembelajaran dan pertumbuhan. Hasil penelitian ini mampu membantu perusahaan untuk mengevaluasi dan merevisi strategi perusahaan. [4]. Namun Balanced Scorecard tidak cukup kuat untuk mengangkat kinerja perusahaan untuk menjadi perusahaan dengan level kinerja great atau excellence. Karena Balanced Scorecard hanya mempunyai 4 perspektif/kategori yang berfokus pada keuangan. Sedangkan Malcolm Baldrige mempunyai 7 kriteria yang harus dipenuhi oleh suatu perusahaan.

Dengan penerapan Baldrige Excellence Framework secara konsisten dan berkelanjutan pimpinan rumah sakit akan mampu memenuhi standar internasional JCI dan mendorong rumah sakit untuk mampu bersaing di era persaingan bebas MEA tahun 2015 (Priyadi, 2015).

Dari persoalan yang dikemukakan, maka diharapkan penerapan kerangka Malcolm Baldrige mampu menyediakan sarana penilaian kinerja yang lebih komperhensif dan menyeluruh sehingga menghasilkan strategi perusahaan dalam meningkatkan mutu manajemen berdasarkan standar pelayanan yang telah ditetapkan oleh pemerintah. Penelitian ini dilakukan di rumah sakit umum daerah (RSUD) Dr. Ashari Pemalang.

\section{METODE}

\subsection{Malcolm Baldrige}

Kriteria Malcolm Baldrige merupakan kerangka yang memberikan kontribusi untuk peningkatan kebutuhan kinerja perusahaan [7]. Kriteria Malcolm Baldrige menyediakan pula kerangka dalam bidang kesehatan untuk mengembangkan dan mengelola kualitas sistem untuk perusahaan layanan kesehatan (Goldstein \& Schweikhart, 2002).

Malcolm Baldrige National Quality Award merupakan penghargaan atas mutu nasional di Amerika Serikat untuk berbagai perusahaan, baik bisnis maupun nonprofit atas kinerja yang ekselen. Nama penghargaan ini diambil dari nama Howard Malcolm Baldride Jr, yang merupakan menteri perdagangan Amerika Serikat pada tahun 1981-1987. Baldrige Criteria merupakan kriteria yang digunakan untuk melakukan penilaian terhadap kinerja ekselen perusahaan (Soemohadiwidjojo, 2015).

Malcolm Baldrige Criteria for Performance Excellence merupakan penuntun bagi suatu perusahaaan untuk mencapai kinerja bermutu tinggi yang terdiri dari 7 kriteria yaitu Kepeminpinan; Perencanaan strategi; Fokus pada Pelanggan; Pengukuran, Analisis dan 
Manajemen Pengetahuan; Fokus pada Tenaga Kerja; Manajemen Proses; dan Hasil (Gaspersz, V., Fontana, 2011).

\subsection{Proses Malcolm Baldrige}

Kerangka kinerja Malcolm Baldrige digunakan sebagai pengukuran kinerja manajemen rumah sakit. Langkah yang

dilakukan adalah:

1. Survei awal terhadap kinerja objek penelitian.

Objek yang digunakan dalam penelitian ini yaitu rumah sakit. Peneliti melakukan survei awal terhadap kinerja manajemen rumah sakit untuk mengetahui kecocokan antara kriteria Malcolm Baldrige dengan objek penelitian.

2. Merancang daftar pertanyaan sesuai dengan balridge assessment.

Pertanyaan yang akan diajukan sesuai dengan item-item didalam kriteria Malcolm Baldrige.

3. Setelah daftar pertanyaan tersusun kemudian dibentuk kedalam kuisioner lalu disebarkan kepada pimpinan rumah sakit untuk melakukan pengisian data. Wawancara dilakukan kepada 4 kepala bidang di rumah sakit seperti: kepala bidang pelayanan, kepala bidang penunjang, kepala bidang TU, dan kepala bidang keuangan.

4. Mengolah data yang diperoleh kemudian skor disesuaikan dengan standar penilaian Malcolm Baldrige. Penilaian dibuat dalam bentuk presentase berdasarkan scoring guidelines MBNQA yang ditunjukkan pada Tabel 1 dan Tabel 2.

Tabel 1. Skor ADLI berdasarkan Malcolm Baldrige

\begin{tabular}{|l|l|}
\hline \multicolumn{1}{|c|}{ Skor } & \multicolumn{1}{c|}{ Keterangan } \\
\hline $0 \%, 5 \%$ & $\begin{array}{l}\text { Pendekatan tidak sistematis,penyebarluasan tidak ada, peningkatan tidak ada, integrasi } \\
\text { dilakukan secara mandiri }\end{array}$ \\
\hline $10 \%, 15 \%$, & $\begin{array}{l}\text { Pendekatan tahap awal, penyebarluasan hanya sedikit, peningkatan bersifat umum, integrasi } \\
\text { dilakukan secara kelompok }\end{array}$ \\
\hline $20 \%, 25 \%$ & $\begin{array}{l}\text { Pendekatan dan penyebarluasan pada item tertentu, peningkatan proses kunci, terintegrasi } \\
\text { dengan kebutuhan organisasi }\end{array}$ \\
\hline $40 \%, 45 \%, 35 \%$, & $\begin{array}{l}\text { Pendekatan efektif pada hampir semua item, penyebarluasan sudah baik, peningkatan } \\
\text { berdasar fakta, integrasi dengan kebutuhan organisasi }\end{array}$ \\
\hline $60 \%, 65 \%$ & $\begin{array}{l}\text { Pendekatan efektif pada hampir semua item, penyebarluasan tanpa kesenjangan, peningkatan } \\
\text { berdasar fakta dan pembelajaran berupa sharing, integrasi berjalan baik dalam menanggapi }\end{array}$ \\
\hline $70 \%, 75 \%$, & iten item kriteria \\
$80 \%, 85 \%$ & $\begin{array}{l}\text { Pendekatan responsif terhadap semua item, penyebarluasan tanpa ada kelemahan, } \\
\text { peningkatan dan inovasi berdasar fakta dan pembelajaran berupa sharing ke semua bagian, } \\
\text { integrasi berjalan baik dalam menanggapi item item kriteria }\end{array}$ \\
\hline $90 \%, 95 \%$, &
\end{tabular}

Tabel 2. Skor LeTCI berdasarkan Malcolm Baldrige

\begin{tabular}{|l|l|}
\hline Skor & Keterangan \\
\hline $0 \%, 5 \%$ & $\begin{array}{l}\text { Tidak ada hasil kinerja organisasi, data tren tidak dilaporkan, informasi perbandingan tidak } \\
\text { dilaporkan, hasil - hasil tidak dilaporkan sesuai dengan misi kunci organisasi /kebutuhan } \\
\text { bisnis }\end{array}$ \\
\hline $10 \%, 15 \%$, & $\begin{array}{l}\text { Beberapa hasil kinerja organisasi dilaporkan, tidak ada/ hanya sedikit data trend dilaporkan, } \\
\text { tidak ada/ hanya sedikit informasi pembanding, hasil - hasil dilaporkan hanya untuk beberapa } \\
\text { area penting dari misi kunci organisasi/ kebutuhan bisnis }\end{array}$ \\
\hline $30 \%, 25 \%, 35 \%$, & $\begin{array}{l}\text { Tingkat kinerja yang baik dilaporkan, tren membaik, tahap awal memperoleh informasi } \\
\text { pembanding, hasil- hasil dilaporkan untuk banyak area penting terhadap misi kunci organisasi } \\
\text { kebutuhan bisnis }\end{array}$ \\
\hline $50 \%, 45 \%, 55 \%$, & $\begin{array}{l}\text { Tingkat kinerja dilaporkan untuk banyak area, tidak ada pola trend yang merugikan, beberapa } \\
\text { trend dan atau tingkat kinerja sekarang dievaluasi terhadap pembanding yang relevan, hasil - } \\
\text { hasil kierja organisasi terbanyak berkaitan dengan kebutuhan pelanggan, pasar, proses }\end{array}$ \\
\hline $60 \%, 65 \%, \begin{array}{l}\text { Kinerja sekarang pada tingkat unggul, trend peningkatan yang unggul dan atau tingkat kinerja } \\
\text { unggul secara konsisten dilaporkan, bukti bukti dari kepemimp inan industri ditunjukkan, hasil } \\
\text { hasil kinerja organisasi semuanya berkaitan dengan kebutuhan kebutuhan utama para } \\
\text { pelanggan, pasar, proses, dan rencana tindakan }\end{array}$ \\
\hline $100 \%, 95 \%$,
\end{tabular}


5. Melakukan penilaian secara keseluruhan untuk mendapatkan hasil akhir berupa level kinerja. Hasil level kinerja dalam Malcolm Baldrige ditunjukkan pada Tabel 3.

Tabel 3. Level kinerja berdasarkan Malcolm Baldrige

\begin{tabular}{|l|c|c|}
\hline \multicolumn{1}{|c|}{ Jenjang predikat } & Skor & Level \\
\hline early development & $0-275$ & \multirow{2}{*}{ Poor } \\
\hline early result & $276-375$ & \\
\hline early improvement & $376-475$ & \multirow{2}{*}{ Average } \\
\hline good performance & $476-575$ & \\
\hline emerging industry leader & $576-675$ & \\
\hline industry leader & $676-775$ & \multirow{2}{*}{ Exellent } \\
\hline benchamark leader & $776-875$ & \\
\hline world leader & $876-1000$ & \\
\hline
\end{tabular}

\subsection{Penerapan dengan Malcolm Baldrige}

Proses dengan kerangka kinerja Malcolm Baldrige adalah:

Mengolah data yang diperoleh kemudian skor disesuaikan dengan standar penilaian Malcolm Baldrige. Penilaian dibuat dalam bentuk presentase berdasarkan scoring guidelines MBNQA.

\section{Langkah pertama:}

Berilah nilai sesuai dengan scoring guidelines MBNQA untuk kriteria dan subkriteria kepemimpinan. Lalu, hitung rata-rata skor yang didapatkan untuk kriteria kepemimpinan. Skor untuk kriteria kepemimpinan ditunjukkan pada Tabel 4.1.

Tabel 4.1 Skor untuk kriteria kepemimpinan

\begin{tabular}{|c|c|c|}
\hline $\begin{array}{c}\text { Kepemimpinan } \\
\text { Sub 1a }\end{array}$ & $\begin{array}{c}\text { Kepemimpinan } \\
\text { Sub 2a }\end{array}$ & $\begin{array}{c}\text { Kepemimpinan } \\
\text { Sub 2b }\end{array}$ \\
\hline $60 \%$ & $60 \%$ & $75 \%$ \\
$55 \%$ & $60 \%$ & $75 \%$ \\
$55 \%$ & $65 \%$ & $80 \%$ \\
$60 \%$ & $60 \%$ & \\
$60 \%$ & $60 \%$ & \\
$65 \%$ & $65 \%$ & \\
$60 \%$ & $60 \%$ & \\
$60 \%$ & $60 \%$ & \\
\hline Rata-rata skor & \multicolumn{2}{|c|}{ Rata-rata skor } \\
Sub 1 & Sub 2 \\
59\% & \multicolumn{2}{|c}{} \\
\hline
\end{tabular}

\section{Langkah kedua:}

Hitung rata-rata nilai yang diperoleh dari setiap kriteria dan masukkan nilai setiap kriteria ke dalam tabel perhitungan Malcolm Baldrige seperti ditunjukkan pada Tabel 4. Selanjutnya, kalikan nilai rata-rata dengan poin maks dan masukkan nilai kedalam kolom "poin item". Lalu, jumlahkan poin item dalam satu kriteria yang sama dan masukkan nilai kedalam kolom "poin kategori". Lakukan penilaian dengan cara yang sama untuk setiap kriteria baik proses maupun hasil.

Keterangan Tabel 4.

Poin maks : nilai tetap berdasarkan standar dari Malcolm Baldrige. 
Skor : rata-rata nilai yang diperoleh dari setiap kriteria.

Poin item : hasil perkalian antara poin maks dan skor

Poin kriteria : hasil penjumlahan antara poin item pada satu kriteria yang sama.

Tabel 4. Perhitungan berdasarkan Malcolm Baldrige

\begin{tabular}{|c|c|c|c|c|}
\hline KRITERIA & POIN MAKS & SKOR & POIN ITEM & POIN KRITERIA \\
\hline Kepemimpinan & 120 & & & 73,80 \\
\hline Kepemimpinan senior & 70 & $59 \%$ & 41,300 & \\
\hline $\begin{array}{l}\text { Pemerintah dan tanggung jawab } \\
\text { sosial }\end{array}$ & 50 & $65 \%$ & 32,500 & \\
\hline Perencanaan strategi & 85 & & & 52,75 \\
\hline Pembangunan strategi & 40 & $61 \%$ & 24,40 & \\
\hline Penyebarluasan strategi & 45 & $63 \%$ & 28,35 & \\
\hline $\begin{array}{l}\text { Fokus pada pasien, pelanggan lain } \\
\text { dan pasar }\end{array}$ & 85 & & & 55,75 \\
\hline $\begin{array}{l}\text { Pasien, pelanggan lain dan } \\
\text { pengetahuan pasar layanan kesehatan }\end{array}$ & 40 & $64 \%$ & 25,60 & \\
\hline $\begin{array}{l}\text { Pasien dan hubungan pelanggan } \\
\text { lainnya dan kepuasan }\end{array}$ & 45 & $67 \%$ & 30,15 & \\
\hline $\begin{array}{l}\text { Pengukuran, analisis dan manajemen } \\
\text { pengetahuan }\end{array}$ & 90 & & & 62,10 \\
\hline $\begin{array}{l}\text { Pengukuran, analisis dan tinjauan } \\
\text { kinerja organisasi }\end{array}$ & 45 & $68 \%$ & 30,60 & \\
\hline $\begin{array}{l}\text { Informasi dan pengelolaan } \\
\text { pengetahuan }\end{array}$ & 45 & $70 \%$ & 31,50 & \\
\hline Fokus tenaga kerja & 85 & & & 64,10 \\
\hline Sistem kerja & 35 & $76 \%$ & 26,60 & \\
\hline Pembelajaran staf dan motivasi & 25 & $77 \%$ & 19,25 & \\
\hline Kesejahteraan staf dan kepuasan & 25 & $73 \%$ & 18,25 & \\
\hline Fokus operasi kerja & 85 & & & 51,00 \\
\hline Proses layanan kesehatan & 45 & $60 \%$ & 27,00 & \\
\hline $\begin{array}{l}\text { Mendukung proses dan perencanaan } \\
\text { operasional }\end{array}$ & 40 & $60 \%$ & 24,00 & \\
\hline Hasil-hasil & 450 & & & 317,70 \\
\hline $\begin{array}{l}\text { Hasil layanan kesehatan dan penyedia } \\
\text { layanan }\end{array}$ & 100 & $72 \%$ & 72,00 & \\
\hline Hasil fokus pasien dan pelanggan lain & 70 & $66 \%$ & 46,20 & \\
\hline Hasil keuangan dan pasar & 70 & $57 \%$ & 39,90 & \\
\hline Hasil sumber daya manusia & 70 & $75 \%$ & 52,50 & \\
\hline Hasil efektivitas organisasi & 70 & $82 \%$ & 57,40 & \\
\hline $\begin{array}{l}\text { Hasil kepemimpinan dan tanggung } \\
\text { jawab sosial }\end{array}$ & 70 & $71 \%$ & 49,70 & \\
\hline TOTAL & 1000 & & & 677,20 \\
\hline
\end{tabular}

\section{Langkah ketiga:}

Melakukan penilaian secara keseluruhan untuk mendapatkan hasil akhir berupa level kinerja. Lakukan penjumlahan untuk semua poin kriteria untuk mendapatkan skor akhir dan mengetahui level kinerja rumah sakit. Seperti terlihat pada Tabel 4 berdasarkan hasil perhitungan, skor yang didapat oleh rumah sakit adalah 677,20 hal ini berarti penilaian kinerja rumah sakit mendapatkan predikat excellent dan termasuk kedalam industry leader.

Dari hasil penelitian yang didapat berdasarkan kerangka Malcolm Baldrige menunjukkan level kinerja pada rumah sakit ini yaitu: industry leader, dengan skor 677,20. Level industy leader merupakan level kinerja yang cukup baik karena perusahaan sudah berada pada level awal excellent. Level kinerja ini bisa ditingkatkan dengan memperbaiki setiap kriteria yang memiliki kekurangan. Untuk mengetahui kriteria mana yang berpengaruh dalam penilaian kinerja manajemen ini maka peneliti melanjutkan pada proses penilaian antar kriteria dengan metode ANP.

\section{Hasil dan Pembahasan}

\subsection{Hasil Penelitian}

Hasil penelitian ini adalah sebuah sistem penilaian kinerja manajemen untuk evaluasi kinerja manajemen bidang kesehatan. Dari hasil penilaian yang telah didapatkan akan dibuat strategi 
peningkatan mutu manajemen dalam menghadapi evaluasi kinerja bidang internasional berdasarkan JCI.

Pada penelitian ini didapatkan hasil level kinerja berupa industry leader dengan skor 677,20. Level kinerja industry leader ini sudah cukup baik karena masuk kedalam level excellent perusahaan. Walaupun terlihat pada kerangka Malcolm Baldrige sudah pada level kinerja industry leader, namun perlu dilakukan evaluasi dengan suatu metode agar validitas sistem dapat diterima.

Hasil ditunjukkan dalam bentuk grafik prioritas kriteria yang harus diperbaiki dalam kinerja manajemen beserta dengan strategi kriteria yang harus diperbaiki.

Tampilan proses pada sistem merupakan tampilan yang menunjukkan proses sebuah penilaian kinerja manajemen bidang kesehatan berjalan sesuai dengan pertanyaan dan kriteria yang telah dimasukkan oleh admin sebelumnya. Adapun beberapa proses yang dilakukan dalam sistem ini seperti: mengisikan data Malcolm Baldrige yang ditunjukkan pada gambar 5.

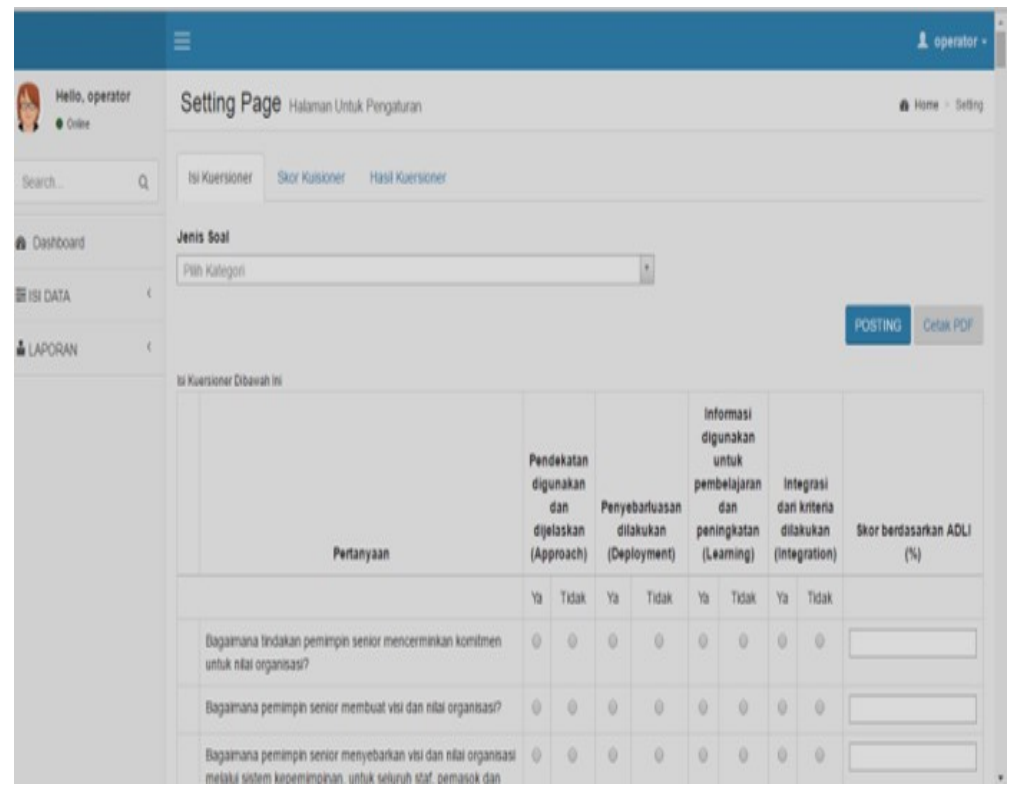

Gambar 5. Isi data Malcolm Baldrige

\subsubsection{Proses dengan Malcolm Baldrige}

Dari hasil penelitian yang didapat berdasarkan kerangka Malcolm Baldrige menunjukkan level kinerja pada Rumah Sakit ini yaitu: industry leader, dengan skor 677,200. Level industy leader merupakan level kinerja yang cukup baik karena perusahaan sudah berada pada level awal excellent. Level kinerja ini bisa ditingkatkan dengan memperbaiki setiap kriteria yang memiliki kekurangan.

\subsubsection{Hasil Malcolm Baldrige}

Tampilan hasil Malcolm Baldrige pada sistem menunjukkan hasil level kinerja pada sistem yaitu "industry leader" yang artinya perusahaan ini berda pada level excellent tahap pertama. Tampilan hasil Malcolm Baldrige dapat dilihat pada Tabel 
Tabel 5. Hasil Malcolm Baldrige

\begin{tabular}{|c|c|c|c|c|}
\hline \multicolumn{5}{|c|}{ HASIL } \\
\hline 1 & Hasil Layanan Kesehatan & 100 & $72 \%$ & 72,00 \\
\hline 2 & $\begin{array}{l}\text { Hasil Fokus Pasien dan pelanggan } \\
\text { lain }\end{array}$ & 70 & $66 \%$ & 46,200 \\
\hline 3 & Hasil keuangan dan pasar & 70 & $57 \%$ & 39,900 \\
\hline 4 & Hasil sumber daya manusia & 70 & $75 \%$ & 52,500 \\
\hline 5 & Hasil efektivitas organisasi & 70 & $82 \%$ & 57,400 \\
\hline 6 & $\begin{array}{l}\text { Hasil kepemimpinan dan } \\
\text { tanggung jawab sosial }\end{array}$ & 70 & $71 \%$ & 49,700 \\
\hline & & 450 & & 317,700 \\
\hline \multicolumn{3}{|c|}{ Total dan kesimpulan } & $\begin{array}{c}677,20 \\
0\end{array}$ & $\begin{array}{l}\text { Industry } \\
\text { leader }\end{array}$ \\
\hline
\end{tabular}

Berdasarkan penelitian sebelumnya mengenai MBNQA, penelitian ini merubah MBNQA 1995 untuk sektor pelayanan kesehatan menjadi penerapan MBNQA 2002 untuk sektor pemerintahan. Selain itu peneliti juga menggunakan Partial Least Square (PLS) untuk menguji instrumen pada kriteria dengan korespondensi satu-ke-satu. Hasilnya, ditemukan hubungan antara:

1. Kepemimpinan (leadereship, strategic planning, customer market) secara positif terkait dengan hasil (human resource, process management, business result).

2. Information and analysis secara positif terkait dengan hasil (human resource, process management, business result).

3. Information and analysis secara positif terkait dengan kepemimpinan (leadereship, strategic planning, customer market) [7].

\section{Kesimpulan}

Dari hasil perhitungan awal sampai akhir pada sistem menunjukkan bahwa tingkat keakuratan sistem yang dibuat sama dengan data pada kenyataan yang telah dihitung secara manual. Ini membuktikan bahwa sistem ini dapat dan layak digunakan sebagai alat bantu para manajer rumah sakit untuk melakukan evaluasi kinerja manajemen. Selain itu, didapatkan pula bahwa berdasarkan hasil penelitian, level kinerja pada Rumah Sakit rumah sakit umum daerah (RSUD) Dr. Ashari Pemalang yaitu industry leader, dengan skor 677,200. Level industy leader merupakan level kinerja yang cukup baik karena perusahaan sudah berada pada level awal excellent. Level kinerja ini bisa ditingkatkan dengan memperbaiki setiap kriteria yang memiliki kekurangan.

\section{REFERENSI}

[1] DepKes RI. (2008). SPM RS.pdf. Jakarta.

[2] Gaspersz, V., Fontana, A. (2011). Malcolm Baldrige Criteria For Perfomance Excellence. Bogor: Vinchristo Publication.

[3] Goldstein, S. M., \& Schweikhart, S. (2002). Empirical Support for the Baldrige Award Support for the Baldrige Award Framework in U . S . Hospitals. Health Care Management Review, 27(1), 62-75. http://doi.org/10.1097/00004010-200201000-00006 
[4] Lin, Q. L., Liu, L., Liu, H. C., \& Wang, D. J. (2013). Integrating hierarchical balanced scorecard with fuzzy linguistic for evaluating operating room performance in hospitals. Expert Systems with Applications, 40(6), 1917-1924. http://doi.org/10.1016/j.eswa.2012.10.007

[5] Menkes RI. (2009). UU RI No 44 Tahun 2009 tentang Rumah Sakit. Peraturan Menteri Kesehatan Tentang Rumah Sakit, 1-24. http://doi.org/UNDANG-UNDANG RI

[6] Meyer Goldstein, S. M., Collier, D. a, Meyer, S. M., \& Collier, D. a. (2001). An empirical test of the causal relationships in the Baldridge Health Care Pilot Criteria. Journal of Operations Management, 19(4), 403-426. http://doi.org/10.1016/S0272-6963(01)00053-5

[7] Priyadi. (2015). Manajemen Rumah Sakit Menghadapi Era Masyarakat Ekonomi Asean Tahun 2015.

[8] Prybutok, V., Zhang, X., \& Peak, D. (2011). Assessing the effectiveness of the Malcolm Baldrige National Quality Award model with municipal government. Socio-Economic Planning Sciences, 45(3), 118-129. http://doi.org/10.1016/j.seps.2010.12.003 